\title{
Integrated management of urban cultural tourism in European small and mid-sized cities: a governance approach
}

\author{
K. Paskaleva-Shapira \& E. Besson \\ Institute for Technology Assessment and Systems Analysis, \\ Karlsruhe Research Centre, Germany
}

\begin{abstract}
Developing urban strategies towards sustainable cultural tourism that preserve local heritage and quality of life requires an effective integration between the urban activities and the actors concerned. Coordinating the efforts, however, poses a major challenge to urban managers and decision-makers, particularly in smaller cities and towns which generally lack the capacities or strategic means to implement 'good urban governance' for sustainable cultural tourism. Understanding the needs and requirements of integrated cultural tourism by the urban authorities and the stakeholders appears necessary. This paper asserts that the complex nature of urban cultural destinations requires an 'integrated management approach' and an 'urban governance framework' of cultural tourism. The notion is based on a critical review of existing state-of-the-art research and policy approaches and the results of a recently conducted pan-European city tourism study.
\end{abstract}

Keywords: cultural tourism, urban governance, integrated management, partnerships, policy.

\section{Introduction}

As a local response to global economic change and shift from industry to service-based economies, many small cities have shown interest in developing urban cultural tourism as a tool of economic development and job creation in their localities (Meethan [1]). Decentralization has significantly favoured the process but such objectives cannot be achieved by mere sectoral marketing or planning strategies; in a context of increased competition between small 
destinations, enhancing the benefits of cultural tourism for urban communities requires an integrated management approach (Go and Govers [2], EC [3]). The latter is often advanced as a key approach to improve transparency and efficiency of decision-making while promoting good governance in cities (Dekker and Van Kempen [4]). However, considering urban cultural tourism in this context is still in its infancy. A significant body of literature has developed regarding the management of the sector in large or famous heritage cities, notably in areas of urban tourism planning [5-7], destination management [8, 9], and urban cultural tourism marketing [10-12]. Yet, literature focusing specifically on the governance of urban tourism is scarce $[13,14]$ with small and mid-sized cities still lacking the attention. This paper highlights the importance of urban cultural tourism in Europe, explores the theories relevant to the sector's integrated management, and discusses the applications in small and mid-sized urban destinations, based on the results of a pan-European study conducted in 2004 and on-going best practice assessments.

\section{Research methods}

The present theme is considered in the context of the findings of a multidisciplinary European research project PICTURE (The Pro-Active Management of the Impacts of Cultural Tourism upon Urban Resources and Economies), supported by the 'City of Tomorrow and Cultural Heritage' of the EU's "6th Framework Research Programme". This project examines the impacts of cultural tourism development upon European cities' economies, heritage resources and quality of life. It explores innovative governance and management styles from two perspectives: (i) how good urban governance can enhance the sustainability of destination development, and (ii) how the management of cultural tourism facilitates for innovative governance styles and stakeholder participation. This paper aims to assess the extent to which cities are successful in applying these potential synergies using both qualitative and quantitative research methods.

At first, a critical literature review was carried out in both science and policy of urban governance and management, sustainable tourism and strategic tourism planning. Based on the outcomes, the "Urban Governance of Cultural Tourism Survey" was designed to understand to what extent European small and midsized cities' representatives are familiar with - and supportive of - current concepts of integrated management and planning of cultural tourism. Cities with known cultural tourism activities and potentials were of primary interest. The relatively high response to the survey (37\%), together with the positive feedbacks from the PICTURE end-users' group after the publication of the survey report, demonstrated the interest of the local authorities in the theme, and the positive impacts of the study on stimulating creativity in management and policy of tourism in the city. Many of the respondents noted that they had no knowledge of the study concepts prior to answering the survey. Some collaborated for a first time with other tourism and cultural actors in order to answer the questions. Others found the issues challenging and hoped that more research findings would be made available to cities, particularly on integrated 
management implementation and best practices. In response to the demand, PICTURE has developed an IT Resource Centre on Best Practices of Urban Cultural Tourism that is available on its website. The current paper builds on these cases to provide policy and management recommendations to the interested cities [15].

\section{Review of existing literature and theory}

\subsection{Cultural tourism's potentials in Europe's small and mid-sized cities}

The emergence of new tourists' experiential values and the provision of interregional transport facilities have allowed urban cultural tourism to become a major market segment in Europe based on built heritage while stimulating considerable development of new tourism products (Boniface [8]). 'Cultural' tourists are increasingly attracted by special events (markets, festivals), creative industries (design, fashion, architecture) and overall urban ambiences of dynamic and bustling activities. Large urban centres are usually better placed on many of these segments (with their large facilities, famous museums, large scale events and conference or business infrastructures). Yet, according to a recent report of the European Travel Commission [16], tourism in smaller cities increases as it holds comparative advantages in terms of quality environment, 'authenticity' and overall creativity in cultural offer provision. Potentially, the benefits of this type of tourism are more directly received by the population, as the residents are usually much involved in the provision of services (guided tours, accommodation, restaurants) and activities.

\subsection{Local impacts}

In cities, cultural tourism is increasingly perceived as a potential means of alleviating the unprecedented crises suffered by many urban centres (Law [17]). As urban tourism grows rapidly, its further development is usually conceived as a "win-win" process, boosting urban growth while supporting a renaissance of housing, since new cultural and leisure activities may serve both tourists and local residents (Ashworth [18]). Adversely, over-development of tourism can lead to rapid erosion of cultural heritage (deterioration, vandalism), damaged visual quality of the landscape due to new constructions, or loss of diversity of the social fabric due to an over-specialization of tourism activities. Especially if quality of place and atmosphere is to constitute the 'Unique Selling Point', tourism development should not harm the resource that motivates it. Yet, preventing damage is far from easy, especially in small and medium-sized cities that unlike large cities, lack the "mass" to absorb the impacts of tourism (Drdacky [19]). In order to manage these potential impacts, carrying capacities must be established. Yet, to-date, carrying capacity has mostly been defined with environmental protection and physical conservation in mind rather than for the conservation and enhancement of the built heritage and quality of life, both of which are of main importance not only to the urban communities, but also to 
tourists [7, 9]. The definition of carrying capacity therefore involves a high subjective, hence contextualised, component. The definition of 'how much is too much', in which city area and with which specific impacts on whom, can only be defined in close cooperation with the local stakeholders to ensure their support and continuous contribution to successful destination development.

\subsection{Stakeholder considerations}

Urban cultural tourism involves a wide range of public and private stakeholders, including local authorities, public agencies dealing with tourism, heritage or environmental quality, local businesses, hotels, travel agents, development agencies, transport operators, city attractions, tourism professional organizations as well as regional and national authorities that provide policies and guidelines with urban impact. The involvement of all in the decision-making process is essential for maximizing the benefits of cultural tourism in the local communities (Svensson et al [20]). According to Bramwell and Sharman [21] and Ritchie and Crouch [22], local residents, citizen organizations and tourists must also be recruited for the cause to ensure the long-term sustainability and competitiveness of the destination. Participation however, needs to be carefully planned to allow decisions to be made in reasonable timeframe. Finding a balance between sustainable community participation and pragmatic constraints of tourism development is challenging and requires regular readjustments in management and development techniques (Barcon [23]).

\subsection{Integrated management}

In a context of increased European competition, a rich heritage alone is not enough to attract tourists. Management, promotion and commercialization of the city offer in a clear cultural tourism strategy have become a must for European small and mid-sized cities [23]. The first step in drafting such strategies is an excellent knowledge of the tourism trends and market potential in the given location. Cultural tourism strategies also need to be realistic and achievable while including distinctive elements. Cultural tourism destinations which rely upon their heritage for their tourism appeal and product must avoid reproducing what has been developed elsewhere, as "me-too" approaches often lead to failures (Hind [24], Richard and Wilson [25]). The ability to combine traditional cultural heritage tourism attractions with contemporary elements in view of local assets and market conditions increases the chances of success. Nevertheless, very few cities throughout Europe have launched genuine strategic projects that include diagnosis, action plan, budget planning and above all implication of major technical, professional and socio-economic actors in the city [23].

Increasing the benefits of urban cultural tourism also requires considering the goals of 'sustainability' in sector's policy and management. Cultural tourism policies must embrace more than short-term economic benefits objectives, and include broader community interests such as quality employment, quality of life, heritage enhancement and sustainable community. Other alternatives include developing a sustainable development plan for the city that includes tourism or 
establishing a Local Agenda 21 that refers specifically to cultural tourism policy objectives (Jackson and Morpeth [26]).

Once clear cultural tourism policies and strategies are established, comprehensive management plans must be drafted, at the neighbourhood or cultural tourism site levels. Visitor management is here key, and should be an integral part of the planning process as it affects various issues such as transportation, traffic control, parking, signage, hotel accommodation or local commerce [16]. Authenticity can be a powerful concept around which to build consensus for action (Vourch [27]). Used either in policy or plans, it allows stakeholders to express common values rather than divergent interests.

\subsection{Governance styles and approaches}

As an emerging field of public action, the integrated management of urban cultural tourism relies on the development of innovative governance styles and arrangements. "Governance" differs from traditional forms of government by including actors representing not only the public sector, but also members of business and voluntary organisations in urban decision-making, most often through public-private partnerships (Svensson et al [20]). A number of studies $[23,28,29]$ highlight the role of local authorities in identifying the players and leaders to make partnerships or collaborations work, including for urban tourism. Not only the city government has the capacities to steer and direct the activities, coordinate the actions, and improve urban tourism policies, but it also maintains the position to promote policy agendas embracing sustainability and governance and involve the citizens and NGOs (Paskaleva-Shapira [28]).

Palmer [14] advocates a "loose-tight" continuum for managing inter- and intra-organisational relationships. Tight governance styles refer to types of partnerships that rely on a prescribed system of rules or some form of legal intervention. In cultural tourism, they include for example public-public and private mixed associations boards and forums, regional agencies, metropolitan or supra-communal wide organisations that involve local authorities, municipal tourism offices, tourism development co-operations and boards, private sector actors, provincial governments and/or heritage agencies (Law [30]). Loose governance systems are characterized by informal understandings among participants, based on trust and mutual interest. They often materialise in urban coalitions or had hoc contractual relationships for the delivery of a common project. Excessively tight or formal governance systems, however, may be inappropriate where a task requires creativity from those being managed. On the other hand, without a 'negotiated environment' and strong leadership, a loose partnership will not work [14].

Governance processes in urban cultural tourism are mostly loose and often unsustainable, especially in small and mid-sized cities where tourism development is sporadic and fragmented [28]. Enriquez-Savagnac [31] also finds that with very few exceptions, local authorities are neither experienced, nor equipped, nor politically motivated to set forth and implement balanced mid and long term programs for tourism development. 


\section{$4 \quad$ Analytical framework}

The PICTURE 2004 Survey Study was structured around four main themes: local prerequisites promoting governance of urban cultural tourism; sector development, management and policy; urban governance and sustainability; and implementing governance of cultural tourism. The overall aim was to identify the main development trends and define the key needs of local authorities for improving cultural tourism management in six directions: (i) strategic development and planning, (ii) sustainable management, (iii) policy development and delivery, (iv) government steering, (v) stakeholder involvement in decisionmaking, and (vi) partnership strategies and implementation.

\section{Findings and recommendations to cities}

The study has found that cultural tourism is a growing industry in many European cities. It also revealed differences in the management and governance structures between the countries. For example in France, the sector is mostly managed by the local municipalities or by public tourism offices; in Germany urban cultural tourism is often supervised by private tourism bureaus appointed by local councils; in the UK, multi-actor partnerships between local authorities, heritage and tourism organisations are common. Governance systems vary in each country as well; urban cultural tourism appears as a much diversified sector insofar as the planning, culture, heritage, tourism, marketing, transport, accommodation and policy-making sectors are involved. Interrelations and responsibilities for policy making thus vary greatly between European cities, regardless of the nature of their local, supracommunal, regional or national administrations. Flexibility in forming innovative governance styles seems a common European opportunity when it comes to cultural tourism: each city has scope in adopting its own governance approach according to the local context, opportunities, cultural tourism development's specifics, and interrelations with other actors and levels of decision-making. However, small and mid-sized localities generally lack the financial and strategic resources to implement good urban governance for sustainable cultural tourism. Missing is a cohesive guidance on how to manage the sector as to create an array of positive impacts for the urban economy and other community assets, such as local heritage and quality of life. A number of propositions for improvements are provided next.

\subsection{Urban cultural tourism strategic development and planning}

Most small and mid-sized cities in Europe lack reliable and/or complete data on sector's dynamics: many too are unaware of the number of tourists and their profiles, the motivation for travel, level of satisfaction and intention to come back. Indicators to measure tourism development vary greatly from city to city, with day visitors being often unaccounted for in official estimations.

To enhance decision-making in the sector, local authorities should, as a critical first step, improve their knowledge and information regarding the role of 
cultural tourism in their urban and regional economies. Dedicated tourism bodies able to coordinate and integrate data sources on tourism are needed to manage complex information. Often, a metropolitan or regional structure is best placed to host such a structure and make strategic projections at the relevant city-region scale (such as the Aire 198 tourism network in the Poitou-Charentes Region, France or the Balcon partnership led by the Halland region, Sweden).

\subsection{Sustainable management}

Results from the survey have shown that most management measures taken by cities relate to built heritage enhancement on the culture side, and to tourism promotion, communication and visitor orientation on the tourism side. In majority of the cities, local authorities are directly in charge of the management, even if the share of mixed public-private companies is significant $(20 \%)$. Different institutions place different emphasis on the management schemes: local authorities and heritage organisations tend to emphasize the needs of the community, while private tourism bureaus and development companies focus on the needs of tourists. These divergences of priorities often pave the way to conflict, therefore the need of collaborative approaches. Existing management plans in cities mostly deal with the clean-up, management and protection of local cultural attractions. Other tools, such as impact assessment and carrying capacity are scarcely used (19\% and 39\% respectively). Authenticity is accounted for in less than half of the surveyed cities' tourism management plans (47\%). Besides, the concept is mostly used for defining the image of the destination as part of the marketing strategies, and little with regard to the sustainable management of the cultural assets of the community.

To overcome the problems, cultural tourism management should become part of the integrated management of the destination. Urban quality of life can be used as a key indicator for reaching a stakeholder consensus. Educational and learning programmes are necessary to encourage responsible travellers and engaged citizens (like in the Eichsfeld regional strategy, Germany). Training programs for tourism personnel and quality control schemes should become part of day-to-day cultural tourism management (see for example the URBAN programme of Malaga, Spain). Impact assessment and innovative policy tools are also necessary to synchronise priority targets and actions among the stakeholders concerned.

\subsection{Policy development and implementation}

In terms of strategic policy development, many cities (80\%) have already developed sustainable development urban plans, including for tourism. Among these, 56\% have a Local Agenda 21 specifically for tourism and 70\% - a formal tourism policy that includes sustainability objectives. Yet, cultural tourism's policy objectives remain scattered and formal policies are missing.

Along with the physical improvement of the cultural attractions, marketing and site preservation (see for example the Bruges traffic plan), local policies for cultural tourism must include elements that support overall community interests 
and citizens' quality of life (such as the Calvia Local Agenda 21 in Mallorca, Spain). Involving actors in all stage of policy making and particularly in defining key issues and policy options is also important.

\subsection{Government steering}

A majority (84\%) of the respondents from all sectors agree on the critical importance of government steering in making tourism partnerships work. The study has revealed that overall, local government is by far the main promoter and enabler of governance for urban cultural tourism. Though the tourism industry appears better placed to secure the investment, local government's role remains essential in ensuring collaboration, openness, and distribution of the benefits among the members of the community.

Yet, local authorities' steering capacities needs a substantial boost. Particularly, in increasing their role in cultural tourism management, impact assessment, learning from 'best practices' and monitoring sectoral development. This could create confidence and earn support from the local community and particularly the private sector, which currently shows a degree of dissatisfaction with their performance. The French examples of Beaunes (Burgundy) or Provins (Ile de France) shows that local authorities can either manage the sector directly or delegate important responsibilities to tourism offices, as long as institutional roles are well defined in destination's long-term strategies and development.

\subsection{Stakeholder involvement in decision-making}

The survey results demonstrate that planning and management expertise is unequally distributed among the various types of urban actors. Impact assessment, carrying capacity or ecological planning for example, are more familiar to private or specialised organisations (such as consultant bureaus, heritage or development agencies) than to most local authorities departments, even those specializing in tourism. Results also show that in the opinion of most respondents, regional and national agencies, as well as research organisations, possess valuable knowledge which is still insufficiently used in urban cultural tourism planning and development. Most commonly involved in practically managing the sector are local authorities, hotel sector, cultural centres and institutions or tourism professional organisations. Often missing are community representatives and the tourists (mentioned by only $31 \%$ of cities).

Integrated management of cultural tourism relies strongly on the participation of the users, both locals and visitors, who are only able to provide qualitative feedback on the quality of the destination and the attractors. Monitoring residents and tourists' satisfaction is essential to improve strategic policies and actions according to the changing demands and perceptions (see for example the Tourism Monitoring Techniques used in Avila, Spain).

\subsection{Partnership strategies and implementation}

While recognized cultural tourism destinations like York, Bern, Bergen or, most recently Belfast have established formal cultural tourism strategies and 
collaborative mechanisms, most cities organise cultural tourism around "loose" relationships (61\%). Very few urban partnerships integrate tourism and cultural capacities; even less aim sharing potential risks in a joint venture (9\%). Leadership is often unclear and management issues are unsettled among the partners. This leads to the ultimate loss of openness (for $74 \%$ of survey respondents) and undermines the efficiency of the partnerships.

In partnerships, critical to maximising the benefits of local collaboration is the sharing of the resources and capacities of the actors. Working out clearly the roles and the responsibilities in management is also important. Good examples of such partnerships are the 'First Stop York' tourism partnership (UK) and the Fidenza Tourism Board (Italy).

\section{Conclusion and framework development}

As this study has highlighted, stakeholder participation and collaboration can be seen as both an improvement and a challenge to traditional forms of decisionmaking in many European cities. Innovative governance styles need to be established to promote a more inclusive and integrated management of the sector which supports diverse and far-reaching community welfare-driven goals. Establishing a strategic policy framework for collaboration by the local authorities to engage with the actors is necessary to facilitate the process. PICTURE has advanced one such framework, the focus of future discussions.

\section{References}

[1] Meethan, K., York: managing the tourist city. Cities, 14(6), pp. 333-342, 1997.

[2] Go, F.M. \& Govers, R., Integrated quality management for tourist destinations: a European perspective on achieving competitiveness. Tourism Management, 21, pp. 79-88, 2000.

[3] European Commission, Enterprise Directorate-General, Tourism Unit, Towards Quality Urban Tourism. Integrated Management (IQM) of Urban Tourism Destinations, Office for Official Publications of the European Communities: Luxembourg, 2000.

[4] Dekker K. \& Van Kempen, R., Urban governance within the Big City Policy. Ideals and practice in Den Haag, the Netherlands. Cities, 21(2), pp. 109-117, 2004.

[5] Law, C.M., Urban Tourism: Attracting Visitors to Large Cities, Mansell Publishing Ltd: London, 1993.

[6] Dennis R. J. \& Fainstein, S. S., (eds). The Tourist City, Yale University Press: New York, 1999.

[7] Page, S. \& Hall, C.M., Managing Urban Tourism, Pearson Education: Harlow, 2003.

[8] Boniface, P., Managing Quality Cultural Tourism, London: Routledge, 1995. 
[9] Glasson, J., Godfrey, K. \& Goodey, B., Towards Visitor Impact Management, Avebury Press: Aldershot, 1997.

[10] Van der Berg, L., Van der Borg, J. \& Van der Meer, J., Urban Tourism. Performance and Strategies in Eight European Cities. Avebury press: Aldershot, 1995.

[11] Jansen-Verbeke, M. \&Van Rekom, J., Scanning museum visitors. Urban tourism marketing. Annals of Tourism Research, 23(2), pp. 364-375, 1996.

[12] Ward, S., Selling Places: The Marketing and Promotion of Towns and Cities 1850-2000, Routledge: London, 1998.

[13] Maitland, R., Creating successful partnerships in urban tourism destinations: the case of Cambridge. Tourism, 50(3), pp. 293-302, 2002.

[14] Palmer, A., Evaluating the governance style of marketing groups. Annals of Tourism Research, 25(1), pp. 185-201, 1998.

[15] EU FP6 PICTURE project, www.picture-project.com.

[16] European Travel Commission Research Group. City Tourism and Culture. The European Experience. Report produced for the Research Group of the European Travel Commission and for the World Tourism Organisation by LAgroup and Interarts. World Tourism Organisation: Madrid, ETC Research Report 2005/1, 2005.

[17] Law, C. M., Regenerating the city centre through leisure and tourism. Built Environment, 26(2), pp. 117-129, 2000.

[18] Ashworth, G. J., Conservation of the built environment in the Netherlands. The Construction of Built Heritage: a North European Perspective on Policies, Practices and Outcomes, ed. Phelps, Ashworth \& Johannson, Ashgate: London, 2001.

[19] Drdacky M.F., Impact and Risks of Tourism in Cultural Heritage Environment. Proc. of the CIVVIH ICOMOS Scientific Conference on Preservation, Development and Monitoring of Historic Cities in the 21st Century. Sofia Avgerinou-Kolonias: Corfu, 2002.

[20] Svensson, B., Vensson, B. \& Flagestad, A., A governance perspective on destination development - exploring partnerships, clusters and innovation systems. Tourism Review, 60(2), pp. 32-37, 2005.

[21] Bramwell, B. \& Sharman, A., Collaboration in local tourism policymaking. Annals of Tourism Research, 26, pp. 392-415, 1999.

[22] Ritchie, J.R.B \& Crouch G.I., The competitive destination: a sustainability perspective. Tourism Management, 21(1), pp. 1-7, 2000.

[23] Barcon, C., Stratégies touristiques des villes. Un délicat équilibre à trouver. Tourisme Urbain, Cahier Espaces, 78, pp. 54-66, 2003.

[24] Hind, D.W., Developing Tourism in the Peripheral sub-regions of Cumbria, UK - A critique of public and private sector initiatives (Chapter 8). Innovation in Tourism Planning, ed. N. Andrews, S. Flanagan, \& J. Ruddy, Dublin Institute of Technology: Dublin, 2002.

[25] Richards, G. \& Wilson, J., Developing creativity in tourist experience: a solution to the serial reproduction of culture. Tourism Management, Article in Press, 2005. 
[26] Jackson, G. \& Morpeth, N., Local Agenda 21 and community participation in tourism policy and planning: future or fallacy. Current Issues in Tourism, 2(1), pp. 1-38, 1999.

[27] Vourch, A., Favoriser l'approche concertée. Espaces naturels, 4, 2003.

[28] Paskaleva-Shapira, K., Innovative partnerships for effective governance of sustainable urban tourism - framework approach, SUT-Governance Deliverable $\mathrm{N}^{\circ} 1,2000$.

[29] Le Galès, P., Le Retour des Villes Européennes. Sociétés Urbaines, Mondialisation, Gouvernement et Gouvernance. Presses de Science-Po: Paris, 2003.

[30] Law, C.M., Urban Tourism. Gareth Shaw and Allan Williams Series Editors: London, pp. 27-38, 1994.

[31] Enriquez-Savagnac, A., The consolidation of the tourism industry: its importance to the global economy", Proc. of the 4th International Symposium of World Heritage Cities, Evora, pp. 98-71, 1997. 